\title{
Sildenafil as a selective pulmonary vasodilator in childhood primary pulmonary hypertension
}

\author{
D Abrams, I Schulze-Neick, A G Magee
}

\begin{abstract}
Primary pulmonary hypertension is a rare disease of childhood, which carries a poor prognosis. Patients often present with severe exercise limitation, and untreated life expectancy is less than 1 year. Pharmacological intervention is directed towards reduction of the raised pulmonary artery pressure with vasodilator treatment, initially with calcium antagonists, although more recently long term prostacyclin treatment has shown benefit in some patients. Heart-lung transplantation remains an option for children with severe disease refractory to therapeutic treatment.

A 4 year old Bangladeshi girl with dyspnoea, cyanosis, and signs of a low cardiac output, is described. Initial treatment with prostacyclin was gradually reduced, and maintenance treatment with oral sildenafil (Viagra; Pfizer) instituted. At follow up 3 months later, her exercise capacity was greatly improved and she continues to enjoy a good quality of life without obvious side effects. In view of the encouraging initial results, this may become an acceptable adjunct in treating this patient group.

(Heart 2000;84:e4)
\end{abstract}

Keywords: primary pulmonary hypertension; sildenafil; prostacyclin

A 4 year old Bangladeshi girl presented with dyspnoea, cyanosis, and signs of a low cardiac output. She had been seen 18 months before with a cyanotic episode, and had been treated with inhaled $\beta$ agonists for presumed bronchoconstriction. There was no other relevant medical or drug history.

Her oxygen saturation was $84 \%$ in air, heart rate was 150 beats per minute, and blood pressure $62 / 40 \mathrm{~mm} \mathrm{Hg}$. The pulmonary component of the second heart sound was accentuated, chest was clear to auscultation, and $3 \mathrm{~cm}$ of pulsatile liver edge was palpable.

ECG showed right atrial enlargement and right ventricular hypertrophy, and chest $x$ ray film showed marked cardiomegaly with normal lung fields. Echocardiography demonstrated a dilated, poorly contracting right ventricle compressing the left ventricle. There was moderate tricuspid valve regurgitation with a Doppler estimated velocity of $5.0 \mathrm{~m} / \mathrm{s}(100 \mathrm{~mm} \mathrm{Hg})$ and a systolic blood pressure of $84 \mathrm{~mm} \mathrm{Hg}$.

She was resuscitated with oxygen and intravenous dobutamine, and prostacyclin at $5 \mathrm{ng} / \mathrm{kg} / \mathrm{min}$ was infused.
At cardiac catheterisation, pulmonary artery systolic pressure was $79 \mathrm{~mm} \mathrm{Hg}$ with a simultaneous systemic systolic pressure of $55 \mathrm{~mm} \mathrm{Hg}$. The mean right atrial pressure was $12 \mathrm{~mm} \mathrm{Hg}$. Administration of nitric oxide at concentrations of up to 20 parts per million in $100 \%$ oxygen produced no change in haemodynamics. Prostacyclin was administered by incremental infusions of up to $20 \mathrm{ng} / \mathrm{kg} / \mathrm{min}$, producing a $10 \%$ fall in pulmonary artery pressure but no increase in cardiac output.

In view of the severity of the pulmonary hypertension and the documented poor response to prostacyclin, oral sildenafil (Viagra; Pfizer) was commenced ( $2 \mathrm{mg} / \mathrm{kg}$, four times a day) with informed parental consent. Serial measurements of mixed venous oxygen saturation demonstrated an average $10 \%$ rise after administration of sildenafil lasting for 60 to 90 minutes. Accordingly, the dose frequency was increased to every four hours. She appeared much better, with an improved exercise capacity, and both prostacyclin and oxygen were successfully discontinued. She was discharged home on oral sildenafil and continues to have improved exercise tolerance four weeks later. Oxygen saturation was $98 \%$, with no fall, during a six minute walk of $160 \mathrm{~m}$. Echocardiography shows a dilated right ventricle but less tricuspid regurgitation. The Doppler velocity is $4.3 \mathrm{~m} / \mathrm{s} \quad(76 \mathrm{~mm} \mathrm{Hg})$ with a simultaneous systolic blood pressure of $87 \mathrm{~mm} \mathrm{Hg}$.

Primary pulmonary hypertension in childhood is a rare aggressive disease, characterised by a progressive elevation of pulmonary artery pressure with secondary right ventricular failure and death. ${ }^{1}$ The initial pathological process is one of vasoconstriction due to vasoreactive medial hypertrophy progressing to intimal fibrosis and a plexiform arteriopathy causing fixed obstruction.

The therapeutic goal is pulmonary vasodilatation while the vessels remain reactive, which is related to both age and the degree of abnormal vascular resistance derived from vessel constriction or fixed arteriopathic obstruction respectively. ${ }^{1}$ Most initial experience has been with the use of calcium antagonists, coupled with supplemental oxygen, anticoagulation, and digoxin treatment. More recently, prostacyclin, a potent pulmonary vasodilator with a short half life, has been used with benefit in these patients. Maintenance treatment is dictated by the acute response to incremental doses of prostacyclin at cardiac catheterisation, allowing assessment of potential reversibility of the raised pulmonary vascular resistance. Patients are thereby divided into two groups: acute responders, many of whom can initially be managed with conventional treatment; and 
non-responders, in whom long term prostacyclin treatment is now the treatment of choice. A recent report by Barst et al demonstrated improved symptoms, haemodynamic data, and survival with long term prostacyclin, in children who failed to respond to acute vasodilatation. Survival at four years in this group was $92 \%$, which compares favourably to historical controls in whom survival was only $29 \%$, and to children who have undergone heart-lung transplantation where five year survival is approximately $40 \% .^{34}$ The mechanism by which prostacyclin achieves a sustained reduction in pulmonary vascular resistance in the absence of acute vasodilatation remains unclear. Although two prospective studies in adult patients ${ }^{56}$ demonstrated significantly improved quality of life and haemodynamic parameters with prolonged prostacyclin treatment, neither group could demonstrate the aetiology of the underlying vascular remodelling. In contrast, the long term use of calcium antagonists is frequently hampered by intolerable side effects, and may prove hazardous or even fatal. ${ }^{2}$

Sildenafil is a selective and potent inhibitor of cGMP-binding cGMP-specific phosphodiesterase (PDE5), which catalyses hydrolysis. ${ }^{7}$ Inhibition of PDE5 increases the cellular levels of cGMP, potentiating vascular smooth muscle relaxation (fig 1), particularly in the lung where PDE5 is found in high concentrations. ${ }^{8}$ It has been used to offset rebound pulmonary hypertension in infants on withdrawal of nitric oxide treatment, ${ }^{9}$ by maintaining raised levels of cGMP in the pulmonary vasculature.

The clinical response in this patient suggests sildenafil may play a role in the management of primary pulmonary hypertension. The tissue specific distribution of PDE5 makes it an attractive alternative or adjunct to current therapies and oral administration avoids the problems of long term prostacyclin infusion.

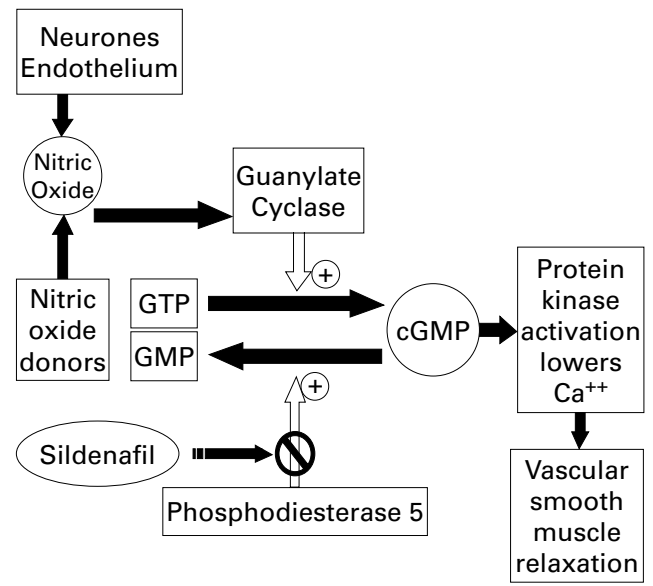

Figure 1 The mechanism of action of sildenafil. cGMP, cyclic guanosine monophosphate; GTP, guanosine triphosphate; GMP, guanosine monophosphate.

1 Barst RJ. Primary pulmonary hypertension in children. In: Rubin LJ, Rich S, eds. Primary pulmonary hypertension. New York: Marcel Dekker, 1996:179-225.

2 Barst RJ, Maislin G, Fishman AP. Vasodilator therapy for primary pulmonary hypertension in children. Circulation 1999;99:1197-208.

3 Conte JV, Robbins RC, Reichenspurner H, et al. Pediatric heart-lung transplantation: intermediate-term results. $\mathcal{F}$ Heart Lung Transplant 1996;15:692-9.

4 Boucek MM, Novick RJ, Bennett LE, et al. The Registry of the International Society of Heart and Lung the International Society of Heart and Lung Heart Lung Transplant 1997;16:1189-206.

5 Barst RJ, Rubin LJ, Long WA et al. A comparison of continuous intravenous epoprostenol (prostacyclin) with continuous intravenous epoprostenol (prostacyclin) with
conventional therapy for primary pulmonary hypertension. conventional therapy for primary pult

6 McLaughlin VV, Genthner DE, Panella MM, et al. McLaughlin VV, Genthner DE, Panella MM, et al.
Reduction in pulmonary vascular resistance with long-term epoprostenol (prostacyclin) therapy in primary pulmonary hypertension. N Engl f Med 1998;338:273-7.

7 Turko IV, Ballard SA, Francis SH, et al. Inhibition of cyclic GMP-binding cyclic GMP-specific phosphodiesterase (type 5) by sildenafil and related compounds. Mol Pharmacol 1999;56:124-30.

8 Sanchez LS, de la Monte SM, Fillipov G, et al. Cyclic GMP-binding cyclic GMP-specific phosphodiesterase (PDE5) gene expression is regulated during rat pulmonary development. Pediatr Res 1998;43:163-8.

9 Atz AM, Wessel DL. Sildenafil ameliorates effects of inhaled nitric oxide withdrawal. Anesthesiology 1999;91:307-10. 